ISSN 2338-1523

E-ISSN 2541-576X

Volume 5 No. 2

November 2017

\title{
PERANAN SISTEM INFORMASI POINT OF SALE PADA TOKO SINAR SAKTI BATAM
}

\author{
Rona Tanjung ${ }^{1)}$ \\ ${ }^{1)}$ Program Manajemen Informatika, Sekolah Tinggi Manajemen Informatika dan Komputer \\ GICI \\ Ronatanjung07@gmail.com
}

\begin{abstract}
ABSTRAK
Toko Sinar Sakti Batam merupakan bidang usaha yang melaksanakan transaksi penjualan dan pembelian barang dalam usahanya, Namun dalam usaha pengolahan data-data transaksi tersebut masih banyak ditemukan kendala-kendala untuk menghasilkan informasi, misalnya dalam pengolahan dan pembuatan laporan-laporan transaksi yang masih dilakukan dengan manual dan membutuhkan waktu yang cukup lama, sehingga sangat tidak efektif dan efisien.

Untuk memudahkan dalam pengolahan data-data transaksi penjualan dan pembuatan laporan maka diusulkan agar membangun sebuah sistem POS (Point of sale) pada Toko Sinar Sakti Batam, yaitu dengan Menggunakan software atau program yang bisa membantu pengolahan data serta penyimpanan data yang terkomputerisasi dengan diciptakannya sebuah program aplikasi sistem POS (Point Of Sale) dengan bahasa pemrograman Visual Basic dan Database MySQL diharapkan dapat memudahkan dalam pengolahan data, laporan maupun penyimpanan data pada Toko Sinar Sakti Batam.
\end{abstract}

Kata Kunci : POS (Point of Sale), Visual Basic, MySQL

\begin{abstract}
Toko Sinar Sakti Batam is a business field which carry out sales and purchases of goods in his business, but the business processing transaction data are still many obstacles to produce information, for example in the processing and manufacturing of transaction reports are still done by hand and requires a long time, so it is not very effective and efficient.

To facilitate the data processing sales transactions and report it is proposed to build a system of POS (Point of sale) at Toko Sinar Sakti Batam, namely the use of software or programs that can help data processing and storage of computerized data with the creation of a program application of POS systems (Point Of Sale) with Visual Basic programming language and MySQL database is expected to ease in data processing, reporting and storage of data on Toko Sinar Sakti Batam.
\end{abstract}

Keywords: POS (Point of Sale), Visual Basic, MySQL 
ISSN 2338-1523

E-ISSN 2541-576X

Volume 5 No. 2

November 2017

\section{PENDAHULUAN}

Kemajuan ilmu pengetahuan yang berorientasi pada pengembangan teknologi merupakan bagian dari kehidupan masyarakat dunia saat ini, sebagian besar dari masyarakat dunia ini sudah tentu tidak ingin ketinggalan teknologi dan informasi, karena dengan teknologi seperti sekarang ini kita dapat mengolah dan memberikan informasi tepat dan efisien. Banyak cara yang dapat kita tempuh untuk dapat mengolah data dan informasi, salah satu caranya dengan memanfaatkan komputer sebagai sarana informasi dengan memanfaatkan Software-sofware yang telah beredar seperti sekarang ini. Kata komputer bukan lagi menjadi kata yang asing, tidak mengherankan jika sekarang ini banyak kita jumpai pengolahan data dan informasi yang menggunakan komputer Pengertian sistem menurut beberapa ahli yaitu, menurut Tata Sutabri (2012:6) pada buku Analisis Sistem Informasi, pada dasarnya sistem adalah sekelompok unsur yang erat hubungannya satu dengan yang lain, yang berfungsi bersama-sama untuk mencapai tujuan tertentu.

Menurut Gordon B. Davis dalam Sutabri (2012:12) menyatakan, sistem bisa berupa abstrak atau fisis. Sistem yang abstrak adalah susunan yang teratur dari gagasan-gagasan atau konsepsi yang saling bergantung. Sedangkan sistem yang bersifat fisis adalah serangkaian unsur yang bekerjasama untuk mencapai suatu tujuan.

Menurut Norman L. Enger dalam Sutabri (2012:12) menyatakan, suatu sistem dapat terdiri atas

JURSIMA

Jurnal Sistem Informasi dan Manajemen kegiatan-kegiatan yang berhubungan guna mencapai tujuan-tujuan perusahaan seperti pengendalian inventaris atau penjadwalan produksi.

Menurut McLeod dikutip oleh Yakub (2012:8) pada buku Pengantar Sistem Informasi, informasi adalah data yang diolah menjadi bentuk lebih berguna dan lebih berarti bagi yang menerimanya.

Menurut Tata Sutabri (2012:22) pada buku Analisis Sistem Informasi, informasi adalah data yang telah diklasifikasikan atau diolah atau diinterpretasikan untuk digunakan dalam proses pengambilan keputusan

\section{Pengertian Sistem Informasi}

Menurut O'Brian dikutip oleh Yakub (2012:17) pada buku Pengantar Sistem Informasi, sistem informasi (information system) merupakan kombinasi teratur dari orang-orang, perangkat keras, perangkat lunak, jaringan komunikasi, dan sumber daya data yang mengumpulkan, mengubah, menyebarkan informasi dalam sebuah organisasi.

Menurut Sutabri (2012:46), sistem informasi adalah suatu sistem didalam suatu organisasi yang mempertemukan kebutuhan pengolahan transaksi harian yang mendukung fungsi operasi organisasi yang bersifat manajerial dengan kegiatan strategi dari suatu organisasi untuk dapat menyediakan kepada pihak luar tertentu dengan laporanlaporan yang diperlukan.

Menurut Sutarman (2012:13), Sistem informasi adalah sistem dapat didefinisikan dengan mengumpulkan, memperoses, 
ISSN 2338-1523

E-ISSN 2541-576X

Volume 5 No. 2

November 2017

menganalisis, menyebarkan informasi untuk tujuan tertentu. Seperti sistem lainnya, sebuah sistem informasi terdiri atas input (data, instruksi) dan output (laporan, kalkulasi).

Dari pendapat di atas dapat disimpulkan bahwa "Sistem informasi merupakan gabungan dari manusia, hardware, software, jaringan komunikasi dan data yang saling berinteraksi untuk menyimpan, mengumpulkan, memproses, danmendistribusikan informasi untuk mendukung pengambilan keputusan dalam suatu organisasi".

\section{Pengertian Penjualan}

Penjualan adalah aktivitas atau bisnis menjual produk atau jasa. Dalam proses penjualan, penjual menyediakan barang dan jasa kemudian memberikan kepada pembeli dengan suatu harga tertentu baik melalui penjualan langsung atau melalui agen penjualan

Penjualan dapat diartikan sebagai kegiatan untuk memenuhi kebutuhan akan barang atau jasa pihak lain, dan pihak lain memperoleh jasa atau barang tersebut Membayar sejumlah uang kepada pihak yang memenuhi barang atau jasa tersebut (Jevrison, 2009)

Penjualan merupakan bagian terpenting dari pemasaran, karena seseorang mengasumsikan bahwa penjualan secara tetap dibutuhkan, sedangkan pengertian penjualan menurut Pederden adalah sebagai proses perorangan pembeli untuk membeli barang/jasa untuk menerapkan perdagangan yang terpenting bagi penjualan

JURSIMA

Jurnal Sistem Informasi dan Manajemen

\section{Tujuan Penjualan}

Tujuan penjualan adalah mendatangkan keuntungan atau laba dari produk-produk atau jasa yang dihasilkan produsen disertai dengan kinerja yang baik serta menjamin kualitas dan mutu produk atau jasa yang akan dijual.Didalam perekonomian, seseorang yang menjual sesuatu akan mendapatkan imbalan berupa uang. Dengan adanya alat penukar berupa uang, manusia lebih mudah memenuhi segala kebutuhannya.

\section{Klasifikasi Penjualan}

Adapun jenis-jenis penjualan adalah sebagai berikut:

1. Trade Selling. Merupakan suatu jenis penjualan yang dilakukan oleh pedagang kepada grosir, tujuan utamanya untuk dijual kembali.

2. Tehnical Selling. Merupakan suatu cara atau usaha untuk meningkatkan penjualan dengan cara memberikan saran kepada konsumen atau pembeli akhir dari barang atau jasanya.

3. New Business Selling. Merupakan suatu usaha untuk membuka transaksi baru dengan cara mengubah caon konsumen menjadi konsumen.

4. missionary Selling. Merupakan suatu bentuk wirausaha dimana pengusaha atau perusahaan memiliki penyalur tersendiri

5. Penjualan secara tunaiPenjualan yang dilakukan pada saat itu juga diterima pembayarannya dan 
ISSN 2338-1523

E-ISSN 2541-576X

Volume 5 No. 2

November 2017

dari pihak produsen

menyerahkan barangnya.

6. Penjualan secara kredit

Penjualan yang dilakukan oleh produsen dengan menerima pembayaran dari konsumen secara tidak langsung. Pihak produsen menyerahkan barangnya kepada pihak konsumen dan pembayarannya dilakukan secara berangsur. Untuk pembelian secara kredit ini konsumen harus memenuhi persyaratanpersyaratan yang telah ditentukan oleh perusahaan.

\section{Visual Basic.NET}

Menurut Sibero (2010:9), Visual Basic.NET adalah bahasa pemrograman yang dikembangkan oleh perusahaan Microsoft. Visual Basic.NET merupakan pengembangan dari versi sebelumnya, yaitu Visual Basic 10, yang memiliki karakteristik mudah untuk dipahami, namun andal dalam mengikuti tren teknologi perangkat lunak. Perbedaan mendasar antara Visual Basic.NET dengan versiversi sebelumnya adalah kemampuan OOP (Object Oriented Programming) yang telah ditanamakan pada Visual Basic.NET. Saat ini Visual Basic.NET telah dikolaborasikan dengan beberapa jenis aplikasi, seperti aplikasi desktop dan aplikasi berbasis web.

\section{Data Flow Diagram (DFD)}

Data Flow Diagram (DFD) merupakan alat pemodelan dari proses analisis kebutuhan perangkat lunak. Dalam DFD dibahas fungsi-fungsi apa saja yang diperlukan oleh suatu sistem dan aliran data yang terdapat diantara proses didalamnya. DFD berguna sebagai alat untuk memverifikasi apakah sistem yang akan dibangun sudah memenuhi kriteria yang diinginkan oleh user atau belum. (Abdullah, 2015).

Dataflow diagram (DFD) adalah representasi grafik yang menggambarkan aliran informasi dan transformasi informasi yang diaplikasikan sebagai data yang mengalir dari masukan (input) dan keluaran (output). Notasi-notasi pada DFD (Edward Yourdon dan Tom DeMarco) adalah sebagai berikut : (Rosa dan Shalahuddin, 2013).

\section{Entity Relationship Diagram (ERD}

Entity Relationship Diagram (ERD) adalah metode konseptual yang mendeskripsikan hubungan antara penyimpanan dalam DFD untuk memodelkan struktur data dan hubungan antar data. (Abdullah, 2015).

ERD adalah suatu permodelan berbasis pada persepsi dunia nyata yang mana terdiri dari kumpulan objek dasar yang disebut dengan entitas (entity) dan hubungan diantara objek-objek tersebut dengan menggunakan perangkat konseptual dalam bentuk diagram. (Lubis, 2016)

ERD adalah suatu diagram untuk menggambarkan desain konseptual dari model konseptual suatu basis data relasional. ERD juga merupakan gambaran yang merelasikan antara objek yang satu dengan objek yang lain dari objek di dunia nyata yang sering dikenal 
ISSN 2338-1523

E-ISSN 2541-576X

Volume 5 No. 2

November 2017

dengan hubungan antar entitas. (Yanto, 2016).

\section{Metode Penelitian}

observasi, wawancara dan penelitian kepustakaan.Sistem informasi yang digunakan yakni sistem pemrograman visual basic 8.0 merupakan IDE (Integrated Development Environment) yang digunakan untuk dikembangkan software dalam IDE inilah yang tersedia berbagai fitur yang memudahkan pemrograman, seperti kompilasi, pengaturan projek, mengedit antar muka secara visual yang dirancang menjadi suatu sistem untuk mempermudah dan mempercepat proses pengolahan pendataan Surat masuk dan surat keluar

\section{Analisis Sistem}

Kegiatan- kegiatan dalam analisis sistem meliputi :

a) Memahami kinerja sistem, pada langkah ini diperlukan langkah sebagai berikut:

1. Memahami kinerja dari sistem yang digunakan

2. Mengatur jadwal penelitian

3. Mengumpulkan hasil penelitian

b) Menganalisa sistem, hal-hal yang perlu dianalisis adalah:

1. Menganalisa kelemahan sistem

2. Menganalisis kebutuhan informasi atau manajemen

c) Membuat laporan hasil analisis, beberapa temuan dan analisis yang telah dilakukan dan disajikan dalam bentuk laporan.

Pada tahap ini dilakukan identifikasi masalah pada sistem yang

JURSIMA

Jurnal Sistem Informasi dan Manajemen sedang berjalan. Dengan demikian, diharapkan penulis dapat menemukan kendala-kendala dan permasalahan yang terjadi pada proses Point of Sales pada toko Sinar Sakti Batam

sehingga peneliti dapat mencari solusi dari permasalahan tersebut.Pada tahap ini dilakukan proses pengumpulan data dengan metode wawancara dan observasi untuk melakukan pengamatan dan analisa terhadap proses Point of Sales pada toko Sinar Sakti sehingga mendapatkan data dan informasi yang dibutuhkan oleh peneliti.

Penulis menggunakan beberapa teknik pengumpulan data sebagai berikut:

1. Interview

Interview yaitu teknik pengumpulan data dengan meminta keterangan dari pihakpihak yang berwenang untuk memberikan keterangan tentang data yang dibutuhkan agar data menjadi lebih lengkap dan jelas.

2. Observasi

Observasi adalah teknik pengumpulan data dengan mengadakan pengamatan dan pencatatan mengenai kegiatankegiatan yang dilakukan.

3. Dokumentasi

Dokumentasi yaitu teknik pengumpulan data dengan cara mengumpulkan data.

4. Studi Pustaka

Studi pustaka adalah teknik pengumpulan data dengan landasan teoritis, penulis mengumpulkan data melalui studi literatur yaitu dengan membaca dan mengumpulkan bahan-bahan teori yang 
ISSN 2338-1523

E-ISSN 2541-576X

Volume 5 No. 2

November 2017

diperlukan dari beberapa sumber/literatur yang berkaitan dengan penelitian dalam penyusunan Tugas Akhir ini.

MySQL

MySQL adalah salah satu jenis database server yang menggunakan SQL sebagai bahasa dasar untuk mengakses databasenya. MySQL termasuk jenis RDBMS (Relational Database Management System). Itu sebabnya istilah seperti tabel, baris dan kolom digunakan pada MySQL

Pada MySQL, sebuah database mengandung satu atau sejumlah tabel. Tabel terdiri dari sejumlah baris dan setiap baris mengandung satu atau beberapa kolom. SQL adalah bahasa standar yang digunakan untuk berkomunikasi dengan basisdata relasional, dan juga merupakan bahasa yang digunakan oleh banyak aplikasi atau tool untuk berinteraksi dengan server basisdata. SQL adalah bahasa fungsional yang tidak mengenal iterasi dan tidak bersifat prosedural. SQL menggunakan perintah-perintah dengan kata-kata sederhana dan mirip dengan bahasa manusia sehari-hari.

Kategori dasar dari perintahperintah yang digunakan dalam SQL untuk melakukan berbagai macam fungsi ada lima yaitu:

1. Data Definition Language

2. Data Manipulation Language

3. Data Query Language

4. Data Administration Commands

5. Transactional Control Commands

JURSIMA

Jurnal Sistem Informasi dan Manajemen
Fungsi yang dapat dilakukan termasuk membangun objek basisdata, memanipulasi objek, mempopulasikan tabel basisdata dengan data, memperbarui data yang sudah ada dalam tabel, menghapus data, melakukan query basisdata, mengontrol akses basisdata dan melakukan administrasi basisdata secara keseluruhan.

Langkah pertama yang harus dilakukan untuk dapat melakukan aktivitas yang berhubungan dengan basisdata adalah dengan melakukan koneksi ke basisdata yang akan digunakan. Membuat koneksi ke basisdata merupakan keharusan agar pemrogram dapat melakukan hal-hal lain yang berhubungan dengan basisdata, seperti menambah data, mengoreksi data, atau menghapus data. PHP tidak menyediakan fungsi khusus untuk melakukan operasi data, sehingga yang digunakan adalah sintaks-sintaks SQL (Structured Query Language). Tahapan untuk melakukan operasi-operasi data adalah sebagai berikut:

1. Koneksi ke basisdata.

2. Permintaan/query data (operasi)

3. Pemutusan koneksi.

$\begin{array}{ccr}\text { MySQL } & \text { sangat } & \text { populer } \\ \text { dikalangan } & \text { developer } & \text { atau }\end{array}$ pengembang perangkat lunak karena MySQL merupakan database server yang free atau gratis dan cepat. Banyak sekali developer-developer, organisasi atau perusahaanperusahaan di dunia yang menggunakan MySQL sebagai database server pada sistem atau 
ISSN 2338-1523

E-ISSN 2541-576X

Volume 5 No. 2

November 2017

aplikasi-aplikasi yang dikembangkan. Dukungan dari perusahaan serta komunitas yang memadai membuat MySQL menjadikan database server paling disukai dan termasuk kategori basisdata yang cepat serta handal sampai dengan saat ini.

ngujian, dan pemeliharaan.

Perencanaan sistem yang lebih baik diperlukan untuk pembuatan program yang baik tak terkecuali dalam pembuatan sistem informasi yang lebih baik. Perencanaan sistem secara terperinci, dilakukan dengan cara:

\section{Hasil dan Pembahasan Usulan Posedur Yang Baru}

Adapun usulan prosedur yang baru pemecahan masalah yaitu sebagai berikut:

1. Pelanggan secara langsung akan memilih barang yang akan dibelinya.

2. Setelah pelanggan siap memilih barang yang mau dibeli,barang tersebut akan diserahkan ke kasir.

3. Bagian kasir akan meng input data penjualan ke dalam database dan menghitung total harga yang dibeli pelanggan dan mencetak nota penjualan barang.

4. Setelah pelanggan melunasi pembayaran,kasir akan menyerahkan nota penjualan kepada pelanggan sebagai bukti transaksi jual beli.

Pada tahap ini dilakukan pengembangan sistem dengan menggunakan model waterfall. Model yang mengusulkan sebuah pendekatan perangkat lunak yang sistematik dan sekuensial yang dimulai pada tingkat dan kemajuan sistem pada seluruh analisis, desain, kode, pe
a. ASI (Aliran Sistem Informasi)
b. Flowchart
c. Diagram Konteks (Context
Diagram)
d. DFD (Data Flow Diagram)
e. ERD (Entity Relationship Diagram)
f. Normalisasi

\section{Flow Map}

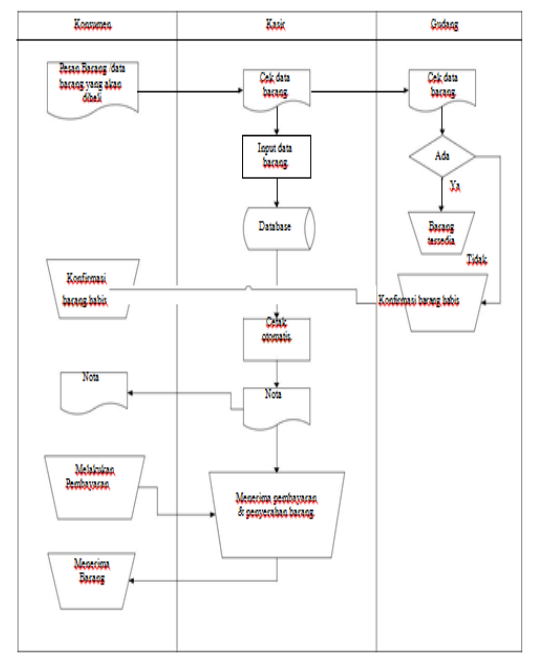

Diagram konteks akan memberi gambaran tentang keseluruhan sistem. Berikut ini adalah gambaran perancangan sistem diagram konteks pada Toko Sinar Sakti Batam : 
ISSN 2338-1523

Volume 5 No. 2

November 2017

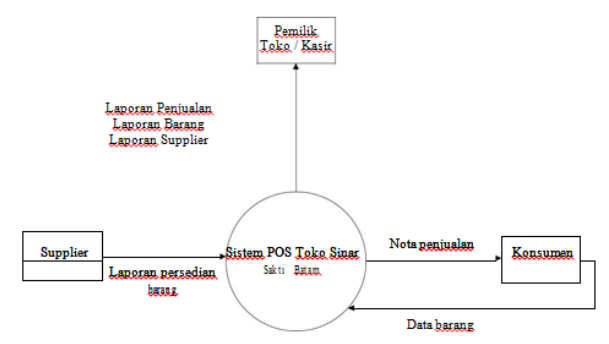

DFD

Pada diagram ini dimana alur data dapat digunakan untukpengambaran analisa maupun sistem yang akan dirancang dan dapat diuraikan sebagai berikut

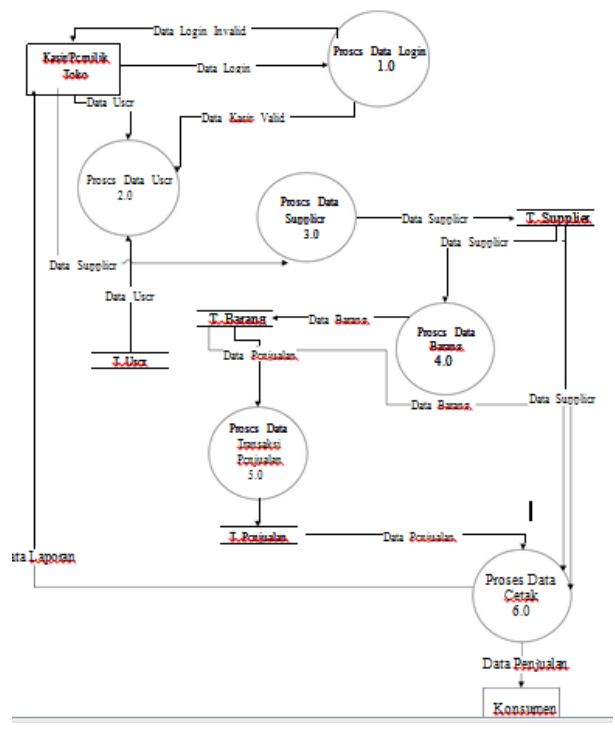

DFD level 1 Proses 1.0 Pengolahan Data Login

JURSIMA

Jurnal Sistem Informasi dan Manajemen

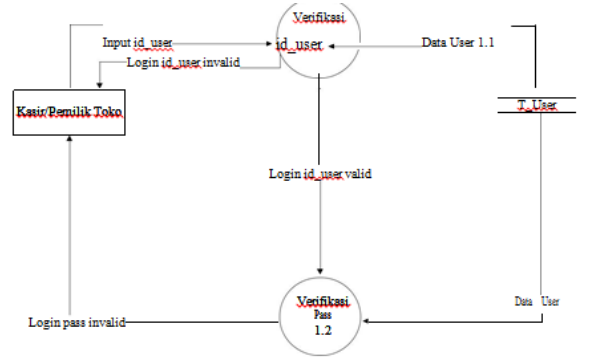

DFD level 1 Proses 2.0 Pengolahan Data User

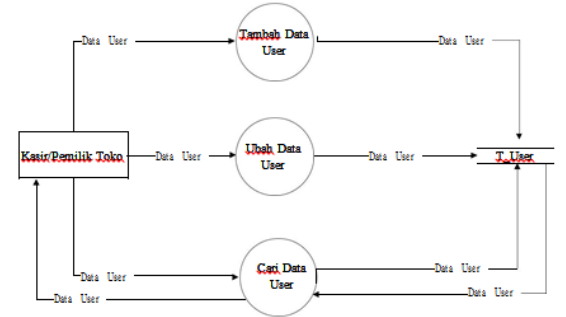

DFD level 1 Proses 3.0 Pengolahan Data Supplier

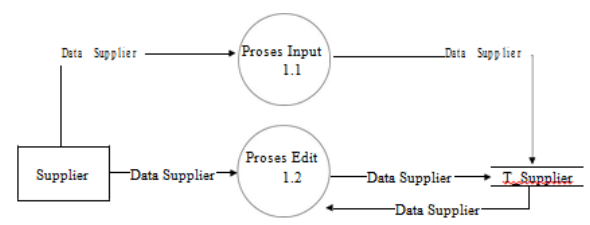

DFD level 1 Proses 4.0 Proses Pengolahan Data Barang

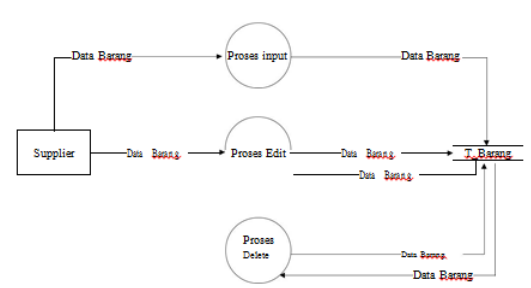

https://ejournal.giciku.ac.id/ STMIK GICI 
ISSN 2338-1523

Volume 5 No. 2

November 2017

DFD level 1 Proses 5.0 Proses

Pengolahan Data Transaksi Penjualan

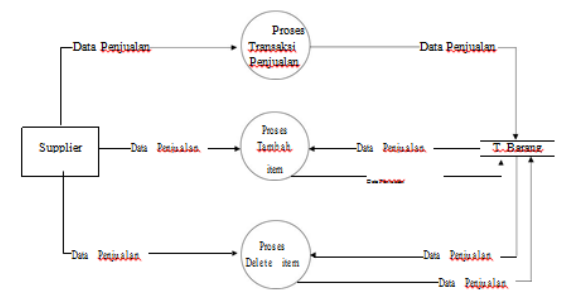

DFD level 1 Proses 6.0 Pengolahan Cetak

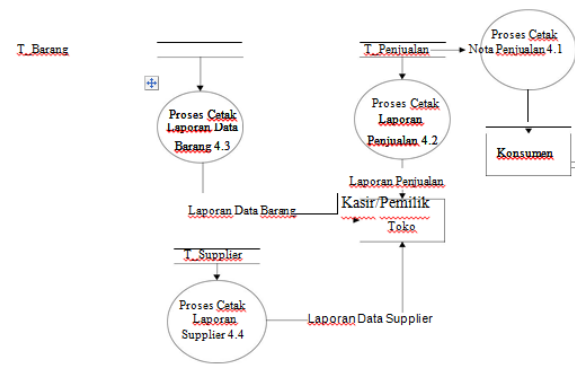

Entity Realtionship Diagram (ERD)

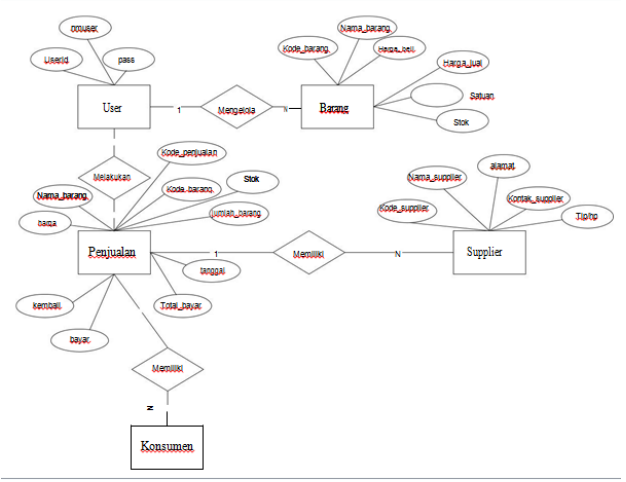

Relasi Antar Tabel

Adapun bentuk relasi antar table dari sistem yang di usulkan adalah sebagai berikut.

JURSIMA

Jurnal Sistem Informasi dan Manajemen

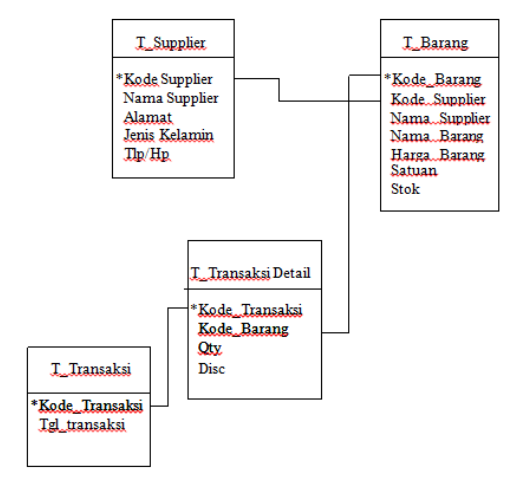

\section{Kamus Data}

Dengan menggunakan kamus data maka seorang analis sistem dapat mendefinisikan data yang mengalir didalam sistem dengan lengkap. Kamus data juga berdasarkan informasi administrasi project yang dirancang dapat dibuat kamus datanya sebagai berikut:

1. Data Transaksi

Nama arus data : Data user

Bentuk data : File

Struktur data : @userid, nmuser, pass

2. Data Supplier

Nama arus data : Data Supplier

Bentuk data : File

Struktur data : @kode_supplier, nama_supplier Jenkel, No Hp

3. Data Barang

Nama arus data : Data Barang

Bentuk data : File

Struktur data :

@ kdbrg, kode_supplier, nama_supplier, nmbrg, hrgbrg, satuan, stok

4. Data Transaksi

Nama arus data : Data Transaksi

https://ejournal.giciku.ac.id/ STMIK GICI 
ISSN 2338-1523

Volume 5 No. 2

November 2017

Bentuk data : File

Struktur data : :@kdtrx, tgltrx

5. Data Transaksi Detail

Nama arus data : Data Transaksi

Detail

Bentuk data : File

Struktur data :

@ kdtrx, kdbrg, qty, disc

\section{Rancangan Prototype/Tampilan}

Berikut rancangan struktur menu yang dibyuatkan dalam sistem terdiri dari menu-menu dan sub menunya dapat dilihat pada gambar di bawah ini.

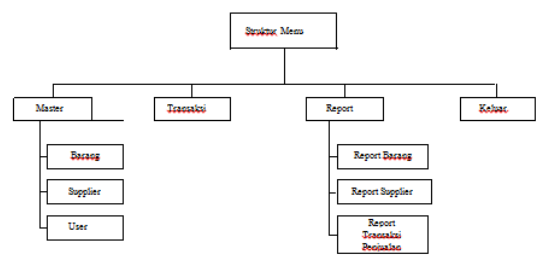

1. Rancangan Input

Rancangan yang form - form yang ada pada sistem pengolahan penjualan pada Toko Sinar Sakti Batam antara lain:

a. Form Login

Form ini digunakan untuk melakukan login administrator untuk menuju ke menu utama.

JURSIMA

Jurnal Sistem Informasi dan Manajemen

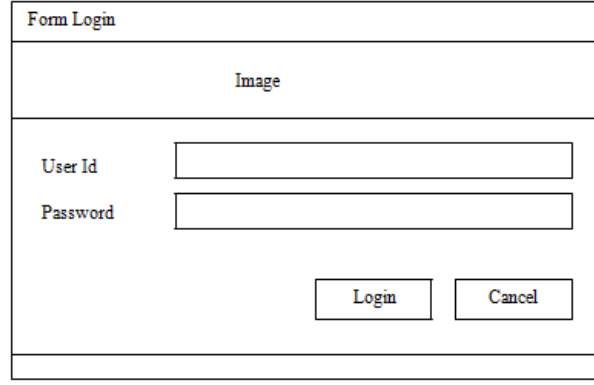

b. Form Menu

Perancangan input menu utama setelah login admin/kasir keluar terdiri dari beberapa menu yaitu: Fungsi master : Kelola supplier, kelola barang, kelola user

Fungsi Transaksi : Transaksi penjualan

Fungsi Report : Laporan barang, laporan supplier, laporan transaksi penjualan Fungsi keluar : Untuk keluar dari sistem.

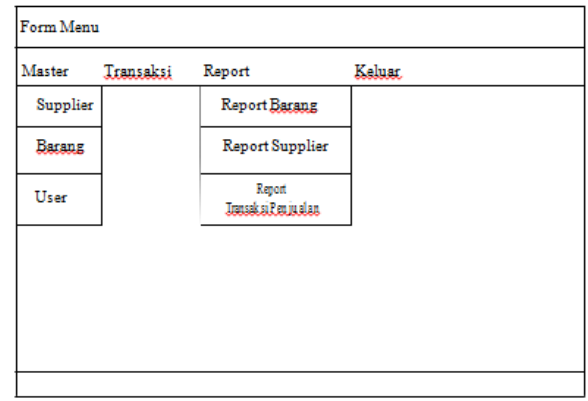

https://ejournal.giciku.ac.id/ STMIK GICI 
ISSN 2338-1523

E-ISSN 2541-576X

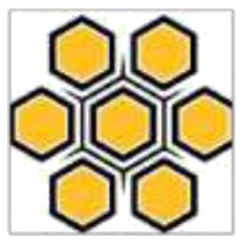

Volume 5 No. 2

November 2017

\section{c. Form Supplier}

Rancangan tampilan data supplier berfungsi untuk memasukkan data supplier tersebut kedatabase.

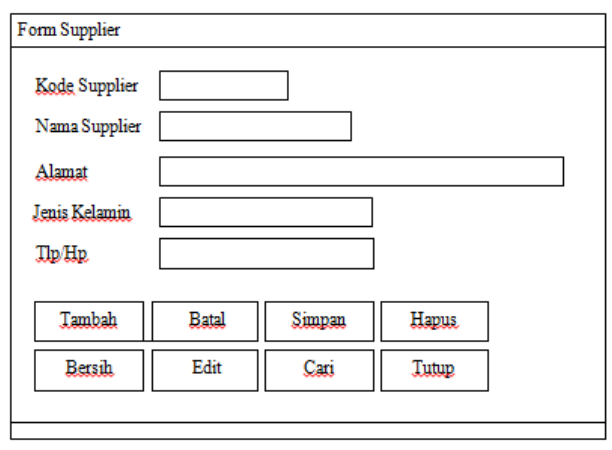

\section{d. Form Barang}

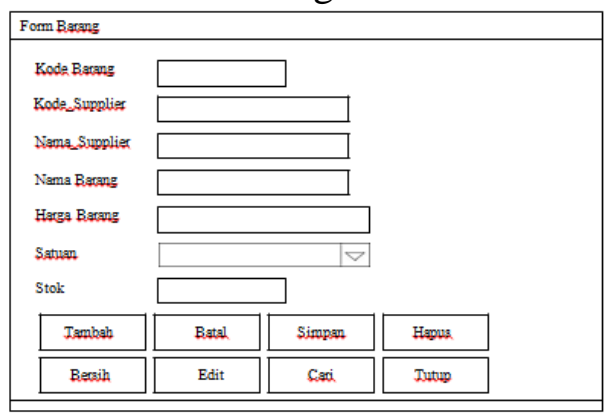

e. Form Use

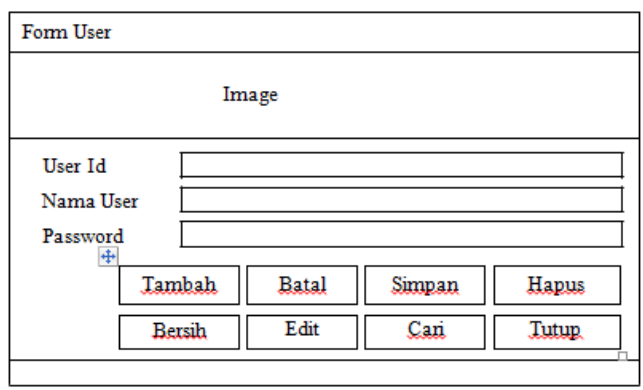

\section{laporan Supplier}

Laporan barang

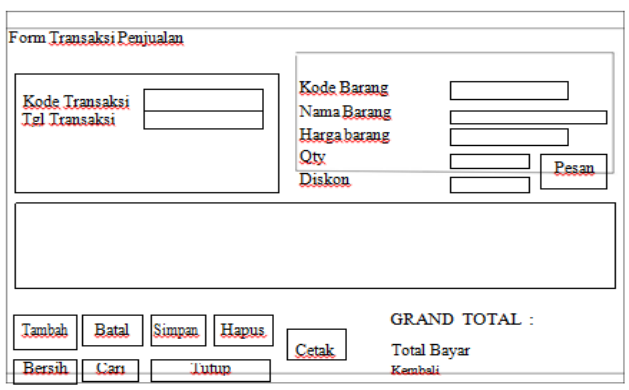

\section{Rancangan Output}

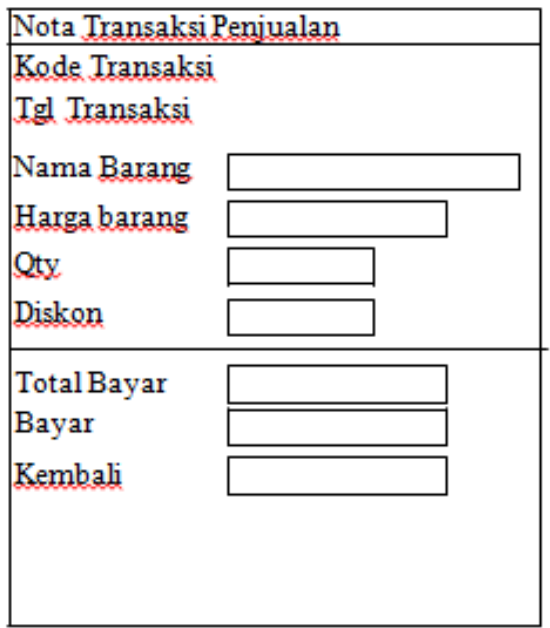

\begin{tabular}{|c|c|c|c|c|c|}
\hline \multicolumn{5}{|c|}{ Laporan Barang } \\
\hline Kode Brang & Nama Barang & Harga Beli & Harga Jual & Satan & Stok \\
\hline 100000 & 100000 & 100000 & 100000 & 100000 & 100000 \\
& & & & & \\
\hline
\end{tabular}

JURSIMA

Jurnal Sistem Informasi dan Manajemen https://ejournal.giciku.ac.id/ STMIK GICI 
ISSN 2338-1523

E-ISSN 2541-576X

Volume 5 No. 2

November 2017

\begin{tabular}{|c|c|c|c|c|}
\hline \multicolumn{5}{|c|}{ Laporan Supplier } \\
\hline Koder Supplier & Kana sinplier & Alamgt & Kontal Supplier & Thp \\
\hline$x x x x x x x x$ & 50000000 & $x 000000 x$ & $x x x y x x x$ & 100000000 \\
\hline
\end{tabular}

Laporan Transaksi Penjualan

\section{KESIMPULAN}

Setelah melakukan analisis, perancangan, beserta pengujian, maka dapat diperoleh kesimpulan sebagai berikut :

1. Sistem yang dibangun dapat mempermudah pengelola dalam melakukan transaksi.

2. Sistem yang dibangun dapat mempermudah dalam membuat laporan.

3. Sistem yang dibangun dapat mempercepat dalam melakukan pencarian data barang.

4. Sistem yang dibangun dapat mempermudah dalam pengecekan stok barang yang ada maupun kosong.

\section{DAFTAR PUSTAKA}

Jogiyanto, H.M, 1989, "Analisa dan Disain Sistem Informasi", Andi Offset, Yokyakarta

Jogiyanto, Hartono. 2010. Analisis dan Desain Sistem Informasi, Edisi III. Yogyakarta : Andi.

Kristanto, Andri, 2003, "Perancangan Sistem Informasi dan Aplikasinya", Gaya Media, Yokyakarta..

JURSIMA

Jurnal Sistem Informasi dan Manajemen

\begin{tabular}{|c|c|c|c|c|c|c|}
\hline \multicolumn{7}{|c|}{ 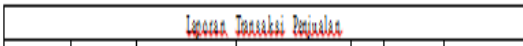 } \\
\hline Sods & I4 & Vara Brats & Hrga berang & 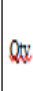 & Distom & Total Hergas \\
\hline$x x x x x x$ & $x x x x x x$ & $x x x x x x$ & $x x x x x x$ & $x x x x$ & $x x x x x x$ & $x x x x x x$ \\
\hline
\end{tabular}

Nugroho, Eko, 2001, "Bahasa-bahasa Pemograman", Andi Offset, Yogyakarta Rusmawan, Uus. 2015. Koleksi Program VB.Net untuk Tugas Akhir dan Skripsi [Edisi Revisi ]. Jakarta : Elex Media Komputindo.

Sibero, Alexander F.K. 2010. DasarDasar Visual Basic.Net. Yogyakarta MediaKom.

Suryantara, I Gusti Ngurah. 2014. Merancang Aplikasi dengan VB.Net 2013.Jakarta : Elex Media Komputindo.

Sutabri, Tata. 2012. Konsep Dasar Informasi. Yogyakarta : Andi.

Sutabri, Tata. 2012. Analisis Sistem Informasi. Yogyakarta : Andi.

Sutarman. 2012. Buku Pengantar Teknologi Informasi. Jakarta: Bumi Aksara.

Udayana, Jusuf, 1994, “Teori Organisasi : Struktur, Desain, dan Aplikasi", Arcan, Jakarta.

Wilkinson,J-W, 1992, "Accounting And Information System", Second Edition Jhon Wikley And Son Inc, Canada

Yakub. 2012. Pengantar Sistem Informasi. Yogyakarta : Graha Ilmu. 